\title{
Global Functional Performance and Caregiver Assistance in Autism and Asperger Syndrome
}

\author{
Michele Gea Guimarães Pozzato', Thais Soares Cianciarullo Minett², \\ Marcelo Rodrigues Masruha1, Luiz Celso Pereira Vilanova1 \\ ${ }^{1}$ Department of Neurology and Neurosurgery, Universidade Federal de São Paulo (UNIFESP), São Paulo, Brazil \\ ${ }^{2}$ Department of Public Health and Primary Care, Cambridge University, Cambridge, UK \\ Email: michele gea@yahoo.com.br
}

Received 29 December 2013; revised 28 January 2014; accepted 27 February 2014

Copyright (C) 2014 by authors and Scientific Research Publishing Inc.

This work is licensed under the Creative Commons Attribution International License (CC BY).

http://creativecommons.org/licenses/by/4.0/

(c) (i) Open Access

\begin{abstract}
Autism and Asperger's syndrome belong to a family of neuro-developmental disorders called Pervasive Development Disorders. The aims of this study were to 1) quantify the overall functional performance and need for caregiver assistance in autism (A) and Asperger's syndrome (AS), 2) compare the findings between groups and to normative data from Brazilian children. Methods: A cross-sectional study was carried out involving 52 children between three and eight years of age diagnosed with either A $(n=26)$ or SA $(n=26)$. The Brazilian version of the Pediatric Evaluation of Disability Inventory was administered. Results: The children with A and AS achieved significantly lower scores than that expected for normality. The children with AS had a significantly better social function than that the children with $A$ had. However, those with A achieved significantly better scores than those with AS on activities related to self-care and mobility, requiring less assistance. Conclusion: While patients with AS are better at social interaction than typical autistic children, they exhibit greater deficits with regard to basic tasks, such as self-care and mobility, requiring greater assistance than children with $A$.
\end{abstract}

\section{Keywords}

Autistic Disorder; Asperger Syndrome; Child Development; Caregivers

\section{Introduction}

Childhood autism and Asperger syndrome are complex developmental disorders, defined primarily in terms of

How to cite this paper: Pozzato, M.G.G., Soares, T., Minett, C., Masruha, M.R. and Vilanova, L.C.P. (2014) Global Functional Performance and Caregiver Assistance in Autism and Asperger Syndrome. Neuroscience \& Medicine, 5, 42-48. 
behavioral disturb [1] [2]. However, summing up the main symptoms, recent studies show that there are other deficits, beyond the behavior sphere, which directly influence the severity and functional prognosis in these individuals [3]-[7].

Difficulties in motor planning and anticipatory adjustments [3] [8], resulting in slow and inefficient motor execution, are described in autism. Deficits in motor coordination [4]-[6], gross and fine motor function were also observed in children on the autistic spectrum [9].

The motor impairments found relate to data on independence and quality of life in these patients. Most individuals affected by this condition remain unable to live independently, and require the support of family or community or institutionalization [1].

Although research has been conducted in recent years addressing motor function in these patients, no studies compare the motor performance of autistic children and children with Asperger syndrome as well as the degree of independence in both conditions. The few findings are extrapolated to the entire spectrum [3]-[9].

Since the losses in individuals with autism and Asperger syndrome cover various areas of development, it is believed to be necessary overall rating for the identification and differentiation of deficits of each clinical condition, which may lead to treatment, resulting in a better prognosis functional.

The aims of this study were to 1) quantify the overall functional performance and need for caregiver's assistance in autism (A) and Asperger syndrome (AS), 2) compare the findings between groups and to normative data from Brazilian children.

\section{Methods}

We performed a cross-sectional study at the Federal University of São Paulo, Brazil. The participants, ages 3 - 8 years, were previously diagnosed with A or AS according to the criteria established by the tenth version of the International Classification of Diseases, ICD 10 [10] and according to the fourth edition of the Diagnostic and Statistical Manual of Mental Disorders, DSM-IV-TR [11]. All participants were clinically followed Ambulatory of Child Neurology, Federal University of São Paulo. The exclusion criteria were unstable clinical condition, presence of comorbidities involving severe physical disabilities, vision or hearing impaired social; situation where the researcher believes the information provided by the caregiver as unrepresentative of reality or noncredible. All guardians provided written consent for the study, which was approved by the Ethics Committee of the Federal University of São Paulo.

The guardians completed questionnaires, containing information about the characteristics of the patient and the caregiver, diagnosis, age, sex, nationality, race, education, rehabilitation therapies, while conducting rehabilitation therapies, kinship caregiver interviewed, education of caregivers interviewed, the caregiver occupation and marital status of parents. The Brazilian version of the Pediatric Evaluation of Disability Inventory (PEDI) was administered in the form of a structured interview with the caregiver and direct observation to evaluate the functional performance.

\section{Data Analysis}

To compare categorical data, the chi-square $\left(\mathrm{X}^{2}\right)$ (without the Yates correction) was used to obeying restrictions Cochran and when they were present, we performed the Fisher exact test.

Differences between means of continuous data were tested using the Mann-Whitney (U) in the case of two samples or the Wilcoxon Signed Rank (W) to a sample.

To see how the scores of the PEDI scale activities were related to each other, according to the study group, perform cluster analysis to identify groups with similar characteristics. The variables were standardized into Z scores. The Euclidean distance coefficient was calculated to measure the dissimilarities between the variables.

A p-value of less than 0.05 was considered to indicate statistical significance, except as a potential problem of multiple comparisons was identified. In this case we used the Bonferroni correction.

All tests were two-tailed. Ninety-five percent confidence intervals (CI) were calculated for the difference between mean values and ORs.

All statistical analyses were performed with the Statistical Package for Social Sciences (SPSS) 11.5.1, except for the Wilcoxon Signed Rank (W) for a sample, where the statistical package used was MINITAB 14.

\section{Results}

Were screened 52 subjects (26 A and 26 AS). There were no statistically significant differences between patients 
with A and patients with SA in relation to sex (92\% versus $96 \%$ boys, Fisher's exact test, $\mathrm{p}=1.000)$, race ( $44 \%$ versus 32\% Whites, X2 $(1)=0.09, \mathrm{p}=0.758)$, birth $(68 \%$ versus $72 \%$ in São Paulo, X2 $(1)=0.09, \mathrm{p}=0.758)$, education ( $56 \%$ versus $60 \%$ grade 1 or more, $\mathrm{X} 2(1)=0.08, \mathrm{p}=0.774)$.

Among patients with A, 56\% were in speech therapy, and among those with AS, 68\%. This difference was not statistically significant $(\mathrm{X} 2(1)=0.764, \mathrm{p}=0.382)$, Moreover, the time of therapy did not differ significantly between the groups of patients (median $=3(\mathrm{AI})$ versus median $=3$ months $(\mathrm{AS}), \mathrm{U}=305.5, \mathrm{p}=0.889$ ).

There were no statistically significant differences among caregivers of patients with A and patients with AS in relation to gender ( $88 \%$ women versus $100 \%$, Fisher's exact test, $\mathrm{p}=0.235$ ), marital status ( $88 \%$ versus $55 \%$ stable, Fisher's exact test, $\mathrm{p}=1.000)$, occupation ( $50 \%$ versus $46 \%$ fixed employment, $\mathrm{X} 2(1)=0.08, \mathrm{p}=0.781$ ), education ( $42 \%$ versus $31 \%$ for four years, $\mathrm{X} 2(1)=0.75, \mathrm{p}=0.388)$.

\subsection{Functional Abilities}

All patients with A had the lowest score in terms of social function (mean =10), whereas all patients with AS had the lowest score in mobility (mean $=10$ ).

To check whether there were differences between the scores on self-care, we used the Mann-Whitney (U). However, to see if there were differences between the scores on mobility and social function, given that the scores obtained by the group A in social function and mobility in the AS group were constant and equal to 10, we use the test function in Wilcoxon Signed Rank (W) for a sample by comparing the sample with a score of 10 .

We found that self-care $(U=149, p<0.001)$ and mobility $(W=351, p<0.001)$ of patients with A were significantly better than in patients with AS. However social function was not statistically different between the two groups of patients $(\mathrm{N}=10, \mathrm{p}=0.100)$.

\subsection{Caregiver Assistance}

All caregivers in the study had the lowest score in terms of assistance in social function (mean $=10$ ), indicating provide more assistance in this area.

Caregivers of patients with AS reported provide significantly more assistance both in the area of self-care (U $=232.0, \mathrm{p}=0.049)$ and in the area of mobility $(\mathrm{U}=198.5, \mathrm{p}=0.010)$ compared with caregivers of patients with A.

\subsection{Comparison between the Means Obtained by Study Patients with Normative Data from Brazilian Children}

To check whether there were differences between the scores on functional abilities as caregiver assistance, we use the Wilcoxon Signed Rank (W) for a sample comparing with the score 50, which represents the expected score for normality.

We found that in all kinds of functional skills and caregiver assistance where the comparison can be made, both the patients as those with AS had significantly lower scores than expected for normality ( $W=0, p<0.001$ ).

\subsection{Activities of Functional Abilities}

\subsubsection{Self Care}

The tasks types of food textures, washing body and face and management of bowel were constant and same in both groups.

Table 1 shows the intergroup comparison of the mean of other self-care activities.

\subsubsection{Mobility}

Table 2 shows the comparison between groups of mean activities that were not listed in the two groups.

The patients with A were able to perform the activity down stairs significantly better than patients with AS.

\subsubsection{Social Function}

Table 3 shows the comparison of mean intergroup social function activities that were not listed in the two groups.

Patients with AS had significantly better social function than patients with A in the activities with $p<0.001$ 
Table 1. Comparison between the scores of self-care tasks obtained by A and AS patients.

\begin{tabular}{ccc}
\hline Task & Statistical Test & $\mathrm{p}$ \\
\hline Use of utensils & $\mathrm{W}=351.0$ & $<0.001$ \\
Use of drinking containers & $\mathrm{W}=0.0$ & 0.002 \\
Tooth brushing & $\mathrm{U}=93.5$ & $<0.001$ \\
Hair brushing & $\mathrm{U}=63.0$ & $<0.001$ \\
Nose care & $\mathrm{U}=33.0$ & $<0.001$ \\
Hand washing & $\mathrm{U}=156.0$ & $<0.001$ \\
Pullover/front-opening garments & $\mathrm{W}=0.0$ & $<0.001$ \\
Fasteners & $\mathrm{U}=95.0$ & $<0.001$ \\
Pants & $\mathrm{W}=148.5$ & 0.300 \\
Shoes/socks & $\mathrm{U}=116.0$ & $<0.001$ \\
Toileting task & $\mathrm{U}=238.0$ & 0.010 \\
Management of bladder & $\mathrm{U}=282.0$ & 0.176 \\
\hline
\end{tabular}

Table 2. Comparison between the scores of mobility tasks obtained by A and AS patients.

\begin{tabular}{ccc}
\hline Task & Statistical Test & $\mathrm{p}$ \\
\hline Car/bus transfers & $\mathrm{U}=242.0$ & 0.057 \\
Up stairs & $\mathrm{W}=0.0$ & 0.009 \\
Down stairs & $\mathrm{U}=195.0$ & $<0.001$ \\
\hline
\end{tabular}

Table 3. Comparison between the scores of social function tasks obtained by A and AS patients.

\begin{tabular}{ccc}
\hline Task & Statistical Test & $\mathrm{p}$ \\
\hline Comprehension of sentence complexity & $\mathrm{W}=0.0$ & $<0.001$ \\
Functional use of communication & $\mathrm{W}=0.0$ & 0.003 \\
Complexity of expressive communication & $\mathrm{W}=0.0$ & $<0.001$ \\
Problem-resolution & $\mathrm{U}=299.0$ & 0.401 \\
Social interactive play (adults) & $\mathrm{W}=253.0$ & $<0.001$ \\
Play with objects & $\mathrm{W}=0.0$ & $<0.001$ \\
Self information & $\mathrm{W}=0.0$ & $<0.001$ \\
Time orientation & $\mathrm{U}=31.5$ & $<0.001$ \\
Domestics tasks & $\mathrm{W}=153.0$ & $<0.001$ \\
Self protection & $\mathrm{U}=273.0$ & 0.167 \\
Community function & $\mathrm{U}=273.0$ & 0.167
\end{tabular}

described in the table.

\subsubsection{Caregiver Assistance}

Caregivers of patients with AS have provided more assistance with self-care activities: use of utensils, use containers of drinking, eating, tooth brushing and hair brushing than caregivers of patients with A.

In the area of mobility all assistance was equal in both groups.

In the social function of the mean activity in support problem-resolution of patients with AS was significantly higher than the average patient with $\mathrm{A}(\mathrm{W}=153.0, \mathrm{p}<0.001)$.

\section{Discussion}

In the present study, the children in both groups (autism and Asperger syndrome) achieved lower scores in 
comparison to normative data for the Brazilian population in the same age range with regard to both functional skills and degree of assistance needed. These findings are in agreement with recent studies suggesting that schoolchildren belonging to the autism spectrum often exhibit delays in motor development [12]-[14]. In a study by Mayes \& Calhoun [14], 50\% to 73\% of children with autism exhibited significant delays in motor function and communication in comparison to normative data for the same age group. Staples \& Reid [9] report that motor skills in children with autism spectrum disorders between 9 and 12 years of age correspond to the performance of healthy children at half of this age range. Data from longitudinal studies demonstrate that children with autism have difficulties not expected for their age with regard to the autonomous performance of activities of daily living [15] [16].

The two groups analyzed herein demonstrated delays in motor function (quantified by mobility and self-care tasks) as well as communication and social interaction (quantified by social function tasks). Thus, both groups require more assistance than expected for their age in all areas of development. In the comparison between groups, the children with Asperger syndrome were significantly more impaired with regard to self-care. Such tasks require motor planning, coordinated movements of different segments of the body, anticipatory postural adjustments, fine motor skills, the control of force applied to objects and cognition (the understanding of why a given task must be performed and what the aim of the task is in the social context) [9] [15].

Mobility in these two groups of developmental disorders has been studied through neurological assessments [17], gait analysis [18], postural control analysis [19], writing analysis [20], gross and fine motor function tests and motor coordination tests [21]-[24]. Studies addressing motor function report that children with autism and Asperger syndrome exhibit considerable motor deficits, such as those identified in the present investigation with a lack of motor coordination especially, which is more related to Asperger syndrome [25]. On the mobility subscale of the PEDI, both groups achieved the minimum score (10 points) for the majority of activities. These findings demonstrate that both groups are equally and severely impaired with regard to tasks involving transfers and locomotion. Studies assessing gross motor function report the possible involvement of basal ganglia, striatal pathways [25] and the cerebellum [26] in motor development disorders found in children belonging to the autism spectrum. Striatal pathways play a fundamental role in initiating movements, whereas variability in the time required to execute movements indicates alterations in the functioning of the cerebellum. Analyzing gait in individuals with autism, Hallet [26] states that the nature of motor deficit in children with autism is more consistent with dysfunction of the cerebellum than the basal ganglia. However, Beversdorf [27] states that, given the neurological and psychiatric complexity of autism spectrum disorders, both regions are likely involved to some extent.

Differences between the two groups were found regarding the tasks of transferring from or to a car or bus and going up and down stairs, for which the children with Asperger syndrome were significantly more impaired. These activities require a greater degree of balance and motor coordination. As mentioned above, individuals with Asperger syndrome demonstrate deficits in motor coordination [2] [10] [11] [28]. Indeed, gross motor tasks that require motor coordination were more compromised in the children with Asperger syndrome in the present study.

Concerning social function, both groups had identical scores with regard to understanding the meaning of words and interactions with children of the same age. These findings demonstrate that the similarities found among individuals belong to the autism spectrum [10] [11]. On the other hand, the children with Asperger syndrome were less impaired than those with autism regarding activities that involve the understanding of complex sentences, expressive communication, social interaction with adults, games with objects, self-information, temporal orientation and participation in household chores. These results are in agreement with findings described in the literature, which reports that children with Asperger syndrome demonstrate a lesser degree of impairment with regard to cognition, social interaction and communication in comparison to those with autism [10] [29].

In the analysis of caregiver's assistance, the lowest scores were found for social function, indicating a greater need for assistance in this area. The findings demonstrate that caregivers constitute a link between children belonging to the autism spectrum and society in terms of function, understanding, problem solving, decision making and safety issues. Larson [30] found that mothers of children with autism who participated intensely in the activities of their children reported greater care with regard to vigilance than physical tasks, as also found in the present study.

Caregivers of children with Asperger syndrome reported a significantly greater degree of assistance with regard to self-care and mobility than caregivers of children with autism, once again demonstrating the poorer per- 
formance of the former group on such tasks. While caregivers of both groups offer degrees of care ranging from supervision to complete assistance, this aspect is rarely mentioned during medical appointments. Thus, motor impairment in autism spectrum disorders is often overlooked, likely due to the more apparent impairment regarding social function. Mobility and self-care deficiencies are more subtle and require more detailed attention and specific questions, such as those found on the PEDI employed in the present study.

Although apparently subtle, problems with mobility and self-care directly affect individuals with autism and Asperger syndrome in both childhood and adulthood, leading to dependence with regard to basic activities of daily living. More directed care in rehabilitation programs and orientation offered to caregivers could minimize the assistance needed and, consequently, the degree of functional dependence of these children.

\section{Acknowledgements}

This study was supported by the Fundação de Amparo à Pesquisa do Estado de São Paulo (FAPESP)—Proc. 2011/14116-5.

\section{References}

[1] Ozand, P.T., Al-Odaib, A., Merza, H. and Al Harbi, S. (2003) Autism: A Review. Journal of Pediatric Neurology, 1, 55-67.

[2] Klin, A. (2006) Autism and Asperger Syndrome: An Overview. Revista Brasileira de Psiquiatria, 28, S3-S11. http://dx.doi.org/10.1590/S1516-44462006000500002

[3] Rinehart, N.J., Bellgrove, M.A., Tonge, B.J., Brereton, A.V., Howells-Rankin, D. and Bradshaw, J.L. (2006) An Examination of Movement Kinematics in Young People with High-Functioning Autism and Asperger's Disorder: Further Evidence for a Motor Planning Deficit. Journal of Autism and Developmental Disorders, 36, 757-767. http://dx.doi.org/10.1007/s10803-006-0118-x

[4] Sahlander, C., Mattsson, M. and Bejerot, S. (2008) Motor Function in Adults with Asperger's Disorder: A Comparative Study. Physiotherapy Theory and Practice, 24, 73-81. http://dx.doi.org/10.1080/15368370701380843

[5] Freitag, C.M., Kleser, C., Schneider, M. and von Gontard, A. (2007) Quantitative Assessment of Neuromotor Function in Adolescents with High Functioning Autism and Asperger Syndrome. Journal of Autism and Developmental Disorders, 37, 948-959. http://dx.doi.org/10.1080/15368370701380843

[6] Green, D., Baird, G., Barnett, Al., Henderson, L., Huber, J. and Henderson, S.E. (2002) The Severity and Nature of Motor Impairment in Asperger's Syndrome: A Comparison with Specific Developmental Disorder of Motor Function. Journal of Child Psychology and Psychiatry, 43, 655-668. http://dx.doi.org/10.1111/1469-7610.00054

[7] Weimer, A.K., Schatz, A.M., Lincoln, A., Ballantyne, A.O. and Tauner, D.A. (2001) Motor Impairment in Asperger Syndrome: Evidence for a Deficit in Proprioception. Journal of Developmental \& Behavioral Pediatrics, 22, 92-101. http://dx.doi.org/10.1097/00004703-200104000-00002

[8] Nazarali, N. and Glazebrook, C.M. (2009) Movement Planning and Reprogramming in Individuals with Autism. Journal of Autism and Developmental Disorders, 39, 1401-1411. http://dx.doi.org/10.1007/s10803-009-0756-X

[9] Staples, Kl. and Reid, G. (2010) Fundamental Movement Skills and Autism Spectrum Disorders. Journal of Autism and Developmental Disorders, 40, 209-217. http://dx.doi.org/10.1007/s10803-009-0854-9

[10] Organização Mundial da Saúde (1998) Classificação Estatística Internacional de Doenças e Problemas Relacionados à Saúde: CID 10. 10ª Edição, Edusp., São Paulo.

[11] American Psychiatric Association (1995) Manual Diagnóstico e Estatístico de Distúrbios Mentais—DSM IV. $4^{\mathrm{a}}$ Edição, Artes Médicas, São Paulo.

[12] Green, D., Baird, G., Barnett, A.L., Henderson, L., Huber, J. and Henderson, S.E. (2009) Impairment in Movement Skills of Children with Autistic Spectrum Disorders. Developmental Medicine \& Child Neurology, 51, 311-316. http://dx.doi.org/10.1111/j.1469-8749.2008.03242.x

[13] Berkeley, S.L., Zittel, L.L., Pitney, L.V. and Nichols, S.E. (2001) Locomotor and Object Control Skills of Children Diagnosed with Autism. Adapted Physical Activity Quarterly, 18, 405-416.

[14] Mayes, S.D. and Calhoun, S.L. (2003) Ability Profiles in Children with Autism: Influenced of Age and IQ. Autism, 7, 65-80. http://dx.doi.org/10.1177/1362361303007001006

[15] Ozonoff, S. and Cathcart, K. (1998) Effectiveness of a Home Program Intervention for Young Children with Autism. Journal of Autism and Developmental Disorders, 28, 25-32. http://dx.doi.org/10.1023/A:1026006818310

[16] Klin, A., Saulnier, C.A., Sparrow, S.S., Cicchetti, D.V., Volkmar, F.R. and Lord, C. (2007) Social and Communication 
Abilities and Disabilities in Higher Functioning Individuals with Autism Spectrum Disorders: The Vineland and the ADOS. Journal of Autism and Developmental Disorders, 37, 748-759. http://dx.doi.org/10.1007/s10803-006-0229-4

[17] Damasio, A.R. and Maurer, R.G. (1978) A Neurological Model for Childhood Autism. Archives of Neurology, 35, 777-786. http://dx.doi.org/10.1001/archneur.1978.00500360001001

[18] Hallet, M., Lebiedowska, M.K., Thomas, S.L., Stanhope, S.J., Denckla, M.B. and Rumsey, J. (1993) Locomotion of Autistic Adults. Archives of Neurology, 50, 1304-1308. http://dx.doi.org/10.1001/archneur.1993.00540120019007

[19] Kohen-Raz, R., Volkmar, F.R. and Cohen, D.J. (1992) Postural Control in Children with Autism. Journal of Autism and Developmental Disorders, 22, 419-432. http://dx.doi.org/10.1007/BF01048244

[20] Beversdorf, D.Q., Anderson, J.M., Manning, S.E., Anderson, S.L., Nordgren, R.E. and Felopulos, G.J. (2001) Brief Report: Macrographia in High-Functioning Adults with Autism Spectrum Disorder. Journal of Autism and Developmental Disorders, 31, 97-101. http://dx.doi.org/10.1023/A:1005622031943

[21] Ghaziuddin, M. and Butler, E. (1998) Clumsiness in Autism and Asperger Syndrome: A Further Report. Journal of Intellectual Disability Research, 42, 43-48. http://dx.doi.org/10.1046/j.1365-2788.1998.00065.x

[22] Ghaziuddin, M., Butler, E., Tsai, L. and Ghaziuddin, N. (1994) Is Clumsiness a Marker for Asperger Syndrome? Journal of Intellectual Disability Research, 38, 519-527. http://dx.doi.org/10.1111/j.1365-2788.1994.tb00440.x

[23] Ghaziuddin, M., Tsai, L.Y. and Ghaziuddin, N. (1992) Brief Report: A Reappraisal of Clumsiness as a Diagnostic Feature of Asperger Syndrome. Journal of Autism and Developmental Disorders, 22, 651-656. http://dx.doi.org/10.1007/BF01046333

[24] Miyahara, M., Tsujii, M., Hori, M., Nakanishi, K., Kageyama, H. and Sugiyama, T. (1997) Brief Report: Motor Incoordination in Children with Asperger's Syndrome and Learning Disabilities. Journal of Autism and Developmental Disorders, 27, 595-603. http://dx.doi.org/10.1023/A:1025834211548

[25] Muller, R.A., Pierce, K., Ambrose, J.B., Allen, G. and Courchesne, E. (2001) A Typical Patterns of Cerebral Motor Activation in Autism: A Functional Magnetic Resonance Study. Biological Psychiatry, 49, 665-676. http://dx.doi.org/10.1016/S0006-3223(00)01004-0

[26] Hallet, M., Lebiedowska, M.K., Thomas, S.L., Stanhope, S.J., Denckla, M.B. and Rumsey, J. (1993) Locomotion of Autistic Adults. Archives of Neurology, 50, 1304-1308. http://dx.doi.org/10.1001/archneur.1993.00540120019007

[27] Beversdorf, D.Q., Anderson, J.M., Manning, S.E., Anderson, S.L., Nordgren, R.E. and Felopulos, G.J. (2001) Brief Report: Macrographia in High-Functioning Adults with Autism Spectrum Disorder. Journal of Autism and Developmental Disorders, 31, 97-101. http://dx.doi.org/10.1023/A:1005622031943

[28] Rinehart, N.J., Bradshaw, J.L., Tonge, B.J., Brereton, A.V. and Bellgrove, M.A. (2002) A Neurobehavioural Examination of Individuals with High-Functioning Autism and Asperger's Disorder Using a Fronto-Striatal Model of Dysfunction. Neuroscience \& Biobehavioral Reviews, 1, 164-177.

[29] Rapin, I. and Dunn, M. (2003) Review Article: Update on the Language Disorders of Individuals on the Autistic Spectrum. Brain \& Developmental, 25, 166-172. http://dx.doi.org/10.1016/S0387-7604(02)00191-2

[30] Larson, E. (2010) Ever Vigilant: Maternal Support of Participation in Daily Life for Boys with Autism. Physical \& Occupational Therapy in Pediatrics, 30, 16-27. http://dx.doi.org/10.3109/01942630903297227 